Revista Destaques Acadêmicos, Lajeado, v. 11, n. 4, 2019. ISSN 2176-3070

DOI: http://dx.doi.org/10.22410/issn.2176-3070.v11i4a2019.2379

http://www.univates.br/revistas

\title{
PROJETO E CONSTRUÇÃO DE UMA MÁQUINA PARA ENSAIO DE FADIGA POR FLEXÃO ROTATIVA
}

\author{
Jhou Maik Trevisan Trampusch ${ }^{1}$, João Pedro Muller ${ }^{2}$, Marcelo André Toso ${ }^{3}$, \\ Carlos Alfredo Gracioli Aita ${ }^{4}$, Vinícius Gonçalves Deon ${ }^{5}$
}

\begin{abstract}
Resumo: A fadiga é um fenômeno de ruptura que altera a estrutura do material de forma localizada, progressiva e irreversível, em virtude de variações de tensões dinâmicas e oscilantes, que podem resultar no surgimento e propagação de trincas ou fraturas de maneira lenta e gradativa após um determinado número de ciclos, levando a ruptura do material. O objetivo deste trabalho é realizar o projeto e construção de uma máquina de ensaio de fadiga (flexão rotativa). Este ensaio mecânico com carregamento cíclico visa prever e prevenir que ocorram falhas mecânicas ocasionadas, muitas vezes, pela escolha equivocada de um material com nível de resistência menor do que a solicitação imposta. Quanto à metodologia do trabalho, primeiramente é realizado o projeto conceitual da máquina, subsequentemente, são realizados desenhos e dimensionamento de diversos componentes mecânicos, por fim, realiza-se a construção do dispositivo. Os resultados mostram que o modelo de máquina foi obtido com sucesso de acordo com o projeto CAD 3D, sendo que a mesma foi validada através de ensaios mecânicos realizados nos corpos de prova juntamente com a medição do nível de vibração estrutural presente na máquina durante os ensaios experimentais. A estrutura demonstrou-se rígida, estável e com baixo nível de vibração estrutural (acelerações na ordem de $0,3 \mathrm{~g}$ ). A instrumentação eletrônica também apresentou bom funcionamento no controle da máquina e na contagem do número de ciclos, tornando-se assim possível a realização de ensaios de fadiga com segurança e confiabilidade.
\end{abstract}

Palavras-chave: Fadiga, Ensaios Mecânicos, Projeto Mecânico, Instrumentação.

1 Acadêmico do Curso de Engenharia Mecânica, Instituto Federal de Santa Catarina. jhou.t@aluno.ifsc.edu.br.

2 Acadêmico do Curso de Engenharia Mecânica, Instituto Federal de Santa Catarina. joao.pm10@aluno.ifsc.edu.br.

3 Doutor em Engenharia Mecânica, Professor do Instituto Federal de Santa Catarina. marcelo. toso@ifsc.edu.br.

4 Mestre em Engenharia, Professor do Instituto Federal de Santa Catarina. carlos.aita@ifsc.edu.br.

5 Mestre em Ciência e Engenharia de Materiais, Professor do Instituto Federal de Santa Catarina. vinicius.deon@ifsc.edu.br. 


\section{INTRODUÇÃO}

A fadiga é a redução gradual da capacidade de carga do componente, normalmente, levando à ruptura do mesmo. Isso ocorre mesmo quando a peça está submetida a esforços menores do que o limite de escoamento do material. A seção crítica de componentes mecânicos submetidos a tensões repetidas ou flutuantes, não compreende, necessariamente, a região onde a carga está aplicada ou onde ocorre o momento fletor de maior magnitude. Diversos autores como, Budynas e Nisbett (2011), Branco, Tavares e Fernandes (1986) e Anderson (2005) descrevem que a falha por fadiga resulta da formação da trinca e sua propagação, a qual se iniciará, normalmente, em uma descontinuidade do material. Essas descontinuidades atuam como concentradores de tensão onde a tensão cíclica atinge seu valor máximo. Geralmente, concentradores de tensão estão presentes nas seções dos componentes onde há mudanças bruscas da seção transversal, chavetas, entalhes, furos, filetes de solda, entre outros, capazes de alterar um estado de tensão plana para um estado triaxial de tensões.

Embora existam alguns equipamentos comerciais destinados a análise de fadiga, os custos de tais dispositivos, aproximadamente $\mathrm{R} \$ 100.000,00$, muitas vezes, inviabilizam a sua utilização em pesquisas relacionadas ao tema em estudo. Desta forma, torna-se necessário o projeto e construção de uma máquina de fadiga com um preço acessível e de construção relativamente simples. O objetivo deste trabalho é realizar o projeto e construção de uma máquina de ensaio de fadiga (flexão rotativa), além de realizar a instrumentação desta máquina e ensaios experimentais para validar o equipamento desenvolvido.

\section{FUNDAMENTAÇÃO TEÓRICA}

A falha por fadiga em um material tem aparência semelhante a uma falha frágil. Considerando os estágios até a falha de um componente, tem-se: a) primeiro estágio, corresponde ao início de uma ou mais microtrincas; b) segundo estágio, tem-se a propagação de micro a macro trincas no material;c) já o terceiro estágio, corresponde a falha do componente de maneira instantânea e repentina (BUDYNAS e NISBETT, 2011). Os primeiros relatos sobre o fenômeno da fadiga foram observados em meados de 1800, através do estudo da falha de eixos em vagões ferroviários submetidos a esforços de pequena amplitude. Os eixos eram produzidos com material dúctil, entretanto, apresentavam aspecto de fraturas frágeis e súbitas. Esse conhecimento baseava-se em experiências resultantes de estudos com cargas estáticas, porém, o fenômeno decorria em função de cargas dinâmicas. $O$ engenheiro alemão August Wohler foi pioneiro na investigação da falha por fadiga. O pesquisador realizou estudos experimentais com carregamentos alternados até a falha do componente (eixos de trens que sofriam flexão rotativa), com o objetivo de definir em qual faixa de tensão não haveria falha do material. Wohler, realizou ensaios de fadiga os quais apontavam que o número de ciclos de tensão variando no tempo 
eram os responsáveis pela ruptura e, ainda, uma tensão limite de resistência à fadiga, o que corresponde ao nível de tensão que suportaria milhões de ciclos de uma tensão alternada. O pesquisador concluiu que materiais sujeitos a carregamentos cíclicos possuem menor resistência mecânica quando comparados a carregamentos estáticos. Como resultado final, pode-se definir o diagrama S-N, também chamado de Curva de Wohler, através da tensão aplicada (S) e do número de ciclos (N) para o colapso (NORTON, 2013). Com base na curva $\mathrm{S}-\mathrm{N}$, é possível observar que a vida do material aumenta com a diminuição da tensão cíclica aplicada, e quando a tensão é reduzida a um determinado valor, a vida do material não é mais afetada.

Quanto a aspectos relacionados à fadiga dos materiais, Willmerding, Hackh e Radovcic (2011) estudaram uma turbina eólica, considerando cargas estáticas e dinâmicas. Os esforços dinâmicos consideravam os efeitos do vento atuando na estrutura. Observou-se que sempre devem ser utilizados fatores de segurança na análise de fadiga, e que a padronização de cálculos é de grande utilidade para aumentar a segurança e confiabilidade do projeto mecânico. Xiang et al. (2012) analisaram falhas por fadiga em um eixo de um motor de tração. Este componente era submetido à alta velocidade, considerando carregamento rotativo. O estudo utilizou o Método dos Elementos Finitos (MEF) para simulação numérica, sendo possível prever a vida em fadiga do eixo da turbina. Neste contexto, Feng et al. (2014) estudaram a fadiga na solda de rotores de turbinas a vapor. Utilizando o MEF, obteve-se resultados de tensão residual próximos dos resultados obtidos experimentalmente. Apesar do estudo do rotor não investigar tensões residuais em solda, os autores concluíram que a solda pode ser a grande responsável pela origem de trincas, que posteriormente, podem levar a falha do componente mecânico. Matheus et al. (2008) desenvolveram um dispositivo para ensaios de flexão rotativa em fios de NiTi, uma vez que esse tipo de ensaio tornou-se padrão para verificar a fadiga em fios com memória de forma. Alvarenga, Mansur e Palma (2002) utilizaram uma metodologia previamente existente para obter as curvas S-N do aço SAE 8620 com ensaios experimentais refrigerados e não refrigerados para a execução do ensaio de fadiga flexo rotativa. Para o ensaio refrigerado, utilizou-se o método Staircase. Esse método submete o corpo de prova a uma determinada tensão, havendo a quebra do elemento, diminui-se a tensão e repete-se o ensaio. Os autores iniciaram o ensaio com tensão superior a resistência a fadiga do material, até que houvesse a ruptura do corpo de prova. Em seguida, os demais corpos de prova foram ensaiados com tensões crescentes e decrescentes. Por fim, os autores aconselham a utilização de refrigeração para a realização dos experimentos para que o comportamento dos materiais não seja influenciado pelo aquecimento do mesmo. Abrahão et al. (2008), abordaram a relevância do estudo da falha por fadiga em materiais submetidos a ciclos repetitivos de tensão ou deformação. Os autores descreveram os mecanismos e formatos de corpos de prova, tipicamente usados nos ensaios de fadiga. Os pesquisadores ressaltaram que o estudo da fadiga realizado em materiais é de 
extrema relevância para todas as áreas da engenharia e proporcionam avanços e soluções para diversas situações impostas nos processos de fabricação de um determinado componente. A trinca (início da falha por fadiga) pode inicia-se devido alguma falha na cristalografia do grão ou a uma deformação severa. As descontinuidades e heterogeneidades do material, bem como os entalhes, são locais onde uma trinca pode iniciar, e o material suporta a deformação descontínua conforme as tensões aplicadas, o número de ciclos, a intensidade das cargas e os possíveis concentradores de tensão. Essa grande quantidade de fatores influencia na vida útil do componente sendo necessária a realização de diversos ensaios de fadiga que irão auxiliar na caracterização das curvas desses componentes (ALBUQUERQUE, 2004; ARAÚJO; SILVA; FARIAS, 2007). Toso et al. (2016) comparam os ensaios de fadiga em dois corpos de prova com geometrias diferentes (componente automotivo). No ensaio experimental, as condições de teste assemelham-se mais as condições reais de uso do componente, submetidos a esforços de flexão, enquanto que para o ensaio normalizado utilizou-se o método dos elementos finitos. Os autores concluíram que o ensaio numérico é útil para definir as curvas de fadiga do material, enquanto que o ensaio experimental prevê a vida em fadiga do componente.

Por fim, destacam-se aspectos relacionados ao ensaio experimental realizado com uma máquina de fadiga. Segundo Souza (1982), os ensaios de fadiga permitem identificar e estabelecer o limite de resistência à fadiga de cada material quando este for submetido à tensão cíclica aplicada acima desse limite. Existem diversos métodos de ensaio e de apresentação dos resultados para determinar a fadiga de um material. Em geral, tais métodos normalmente utilizam a metodologia proposta pela norma ASTM STP-566 (1974) podendo ser puramente baseados em testes experimentais. Os dados obtidos durante $o$ ensaio são dispostos graficamente, dividindo a curva de fadiga basicamente em dois estágios: fadiga de baixo ciclo (inferior a $10^{3}$ ciclos para os aços) e fadiga de alto ciclo (acima de $10^{3}$ ciclos). O limite de resistência a fadiga (Se) é apresentado a partir de $10^{6}$ ciclos ou quando a curva atinge um patamar onde não há mais variações da tensão (usualmente chamado de vida infinita).

Quanto a máquina de ensaio de fadiga, Ávila (2005) cita que em máquinas de ensaio de flexão rotativa, todo o corpo de prova está submetido a tensões alternadas puras. Destaca-se que para esse tipo de ensaio a tensão média é nula e a amplitude da tensão é igual a máxima solicitação aplicada. Segundo Padilha (2004), a região em rotação entre as partes sob flexão está submetida a um momento fletor em seu comprimento. Com isso, qualquer área da superfície do corpo de prova está sujeita a uma reversão de tensão completa. Quando o corpo de prova está com uma compressão máxima na parte superior, a inferior estará com uma tração máxima e assim, sucessivamente.

A máquina de ensaio de fadiga apresentada neste artigo é constituída basicamente por um contador de ciclos eletrônico que registra as revoluções do corpo de prova até a fratura do componente, um motor responsável pela geração 
da rotação da máquina e um dispositivo aplicador de carga que aplica a tensão requerida para cada teste. Por fim, utilizam-se suportes (mancais), responsáveis pela fixação dos corpos de prova que serão caracterizados experimentalmente. Informações do projeto mecânico e instrumentação da máquina de fadiga serão abordados em sessões subsequentes.

\section{METODOLOGIA}

As etapas que compreendem o projeto e construção da máquina de fadiga estão dispostas no fluxograma da Figura 1.

Figura 1. Fluxograma representando a metodologia utilizada no projeto e construção da máquina de fadiga.

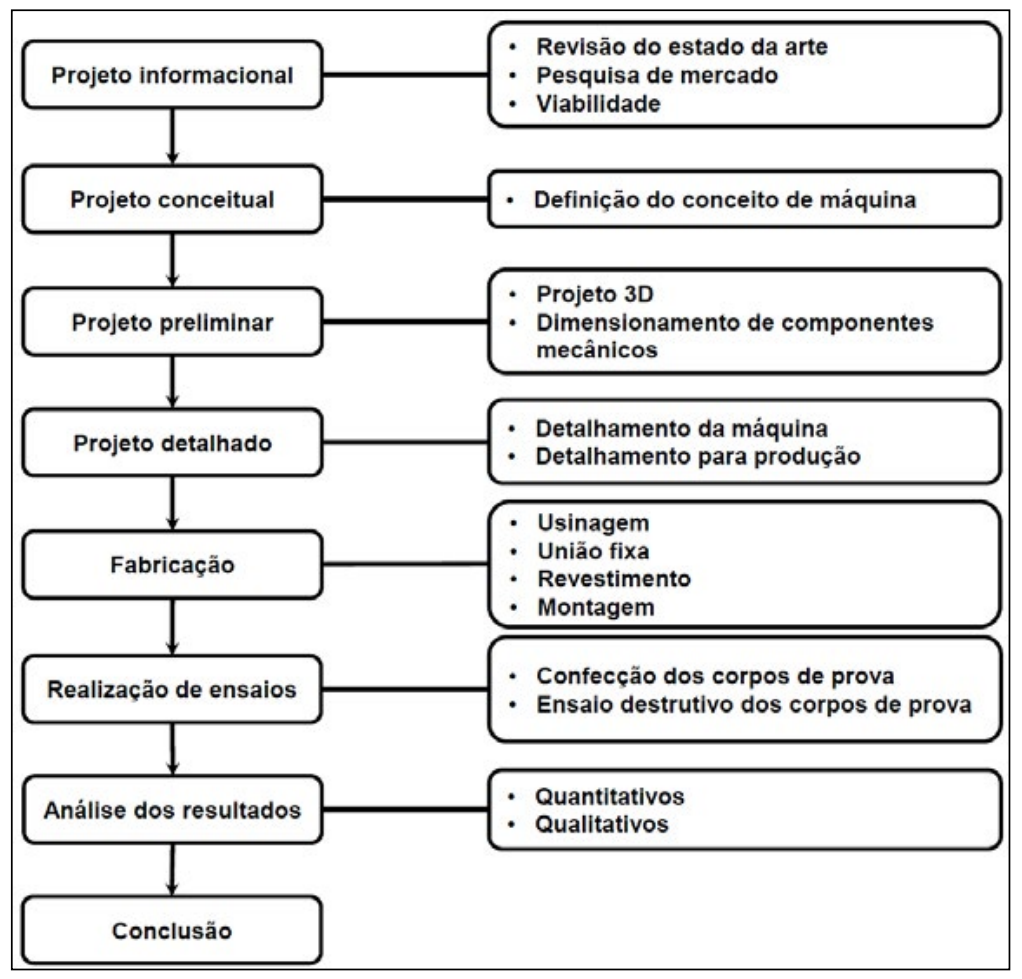

Fonte: Do autor (2019).

A partir do projeto informacional, que foi a fase de pesquisa e análise de todos os aspectos envolvidos para a obtenção do conceito da máquina de fadiga, pode-se definir um objeto de estudo. Em posse dos dados da pesquisa, na etapa de projeto conceitual, obteve-se, através de um brainstorming, um modelo conceitual da máquina, o qual se comprovou ser viável economicamente. Com o conceito de máquina definido, iniciou-se o projeto preliminar onde foi constituído o modelo 3D da máquina a ser construída, bem como a seleção e 
dimensionamento de diversos componentes mecânicos. Subsequentemente, o projeto detalhado foi executado de forma que tanto os componentes quanto a máquina fossem produzidos e montados. A partir da conclusão da etapa de detalhamento do projeto mecânico, deu-se início a fabricação da máquina, onde foram utilizados diversos os processos:

- Usinagem, na confecção das partes individuais e na limpeza das superfícies para receber a camada de revestimento;

- Soldagem, para união das partes usinadas;

- Pulverização, para pintura do conjunto sólido; e

- Montagem, onde uniram-se o conjunto sólido com os componentes selecionados e calculados.

Concluída a etapa de montagem da máquina de fadiga, iniciou-se a confecção dos corpos de prova utilizados nos testes experimentais, utilizando um torno CNC (modelo Romi GL240) os quais seguiram o modelo apresentado por Andersen et. al (1997), conforme apresentado na Figura 2.

Figura 2. Modelo detalhado do corpo de prova.

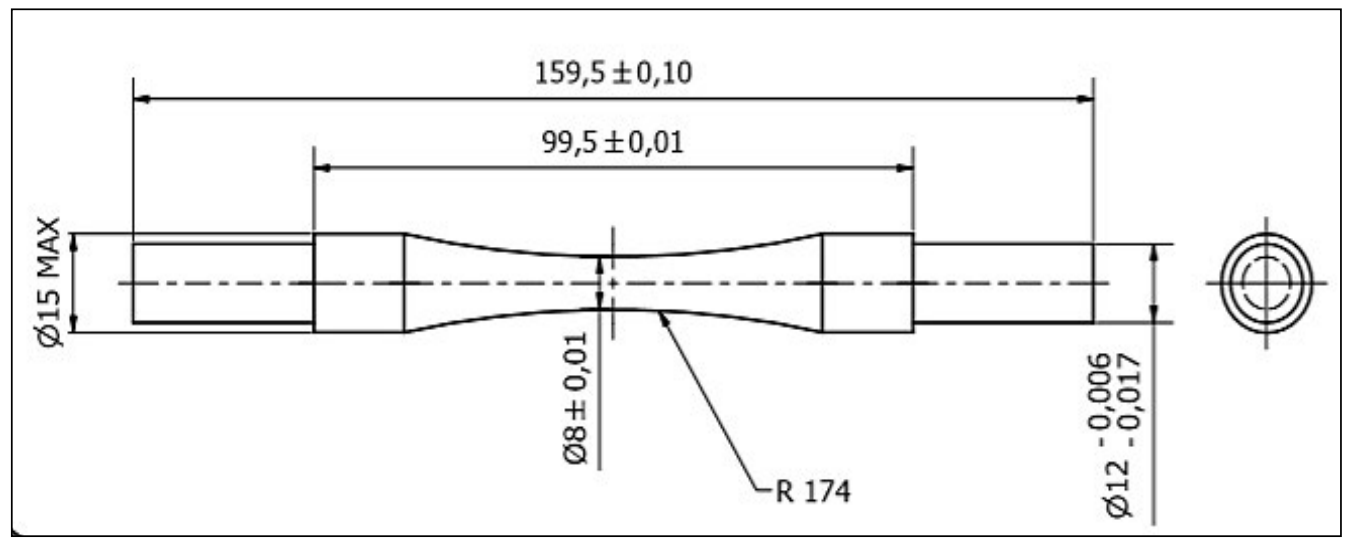

Fonte: Do autor (2019).

Após a confecção dos corpos de provas, realizou-se uma série de testes de fadiga sobre os mesmos, com cargas variadas. Nestes testes analisaram-se os níveis de vibração estrutural da máquina (direções $x, y$ e $z$ ), assim como, o possível aquecimento e desalinhamento dos mancais de rolamento além da verificação dos componentes eletrônicos de controle da máquina de fadiga.

\section{RESULTADOS E DISCUSSÕES}

$\mathrm{Na}$ etapa de projeto conceitual, diversos modelos de máquinas para ensaio de fadiga foram estudados. A partir destes modelos, definiu-se que a 
máquina a ser projetada e construída seria do tipo flexão-rotativa, com a carga aplicada em balanço ao corpo de prova. Optou-se por este modelo de máquina em função de critérios de funcionalidade e fabricação mecânica. Com o conceito de máquina definido, foi possível iniciar a etapa de projeto, modelagem e detalhamento dos componentes a serem empregados. A Figura 3 representa o modelo 3D de máquina, realizado na etapa do projeto preliminar.

Figura 3. Representação 3D do conceito da máquina de fadiga.

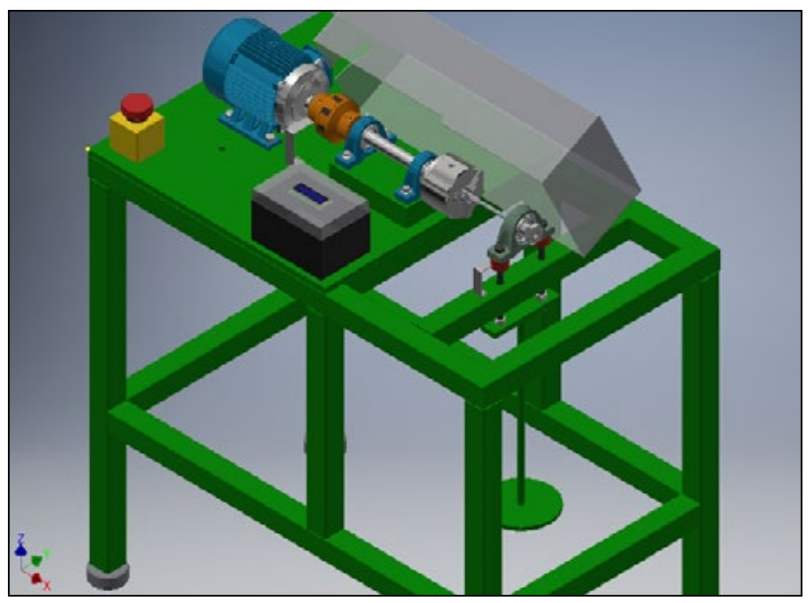

Fonte: Do autor (2019).

O funcionamento da máquina de fadiga ocorre em função da carga aplicada na extremidade em balanço do corpo de prova e da rotação por meio do torque do motor. A carga na extremidade gera forças de tração na parte superior e de compressão na parte inferior do corpo de prova e, ao passo em que o motor gira completando meias voltas, essas tensões se invertem, produzindo esforços oscilantes, sendo esta, a característica principal que resulta no fenômeno de fadiga.

\subsection{Dimensionamento e seleção dos elementos mecânicos e elétricos}

Nesta etapa do projeto realizou-se o dimensionamento e seleção dos componentes mecânicos da máquina de fadiga, buscando garantir o funcionamento efetivo e evitar que possíveis falhas possam ocorrer.

\subsubsection{Motor e inversor de frequência}

O motor elétrico selecionado para a máquina de ensaio de fadiga é da marca WEG e trifásico. Este motor foi selecionado por apresentar alta eficiência, baixo custo e ser robusto o suficiente para realização dos ensaios experimentais 
de fadiga. Os dados técnicos do motor elétrico selecionado para a máquina de fadiga são apresentados na Tabela 1.

Tabela 1. Informações técnicas do motor elétrico utilizado na máquina de fadiga.

\begin{tabular}{cc}
\hline Informações & Descrição \\
\hline Fabricante & WEG \\
Modelo & WEG-11368627 \\
Potência & $1 \mathrm{cv}$ \\
Torque máximo & $4,03 \mathrm{~N} \cdot \mathrm{m}$ \\
Frequência & $60 \mathrm{~Hz}$ \\
Rotação máxima & $1730 \mathrm{rpm}$ \\
Polaridade & 4 polos \\
Tensão elétrica & $220 / 380 \mathrm{~V}$ \\
Grau de proteção & $\mathrm{IP55}$ \\
\hline
\end{tabular}

Fonte: Do autor.

A rotação do motor influencia diretamente na velocidade dos testes de fadiga. Portanto, fez-se necessário a utilização de um inversor de frequência para o controle da rotação, e em consequência, da velocidade dos testes experimentais. Outra funcionalidade do inversor de frequência é o controle de acionamento do motor, onde foram utilizadas as portas digitais do inversor em conexão com um arduíno para controlar este componente. $\mathrm{O}$ inversor de frequência selecionado para a máquina de fadiga, é o modelo CFW500 da WEG. Este modelo foi selecionado por apresentar boa confiabilidade, facilidade de programação e configurações adequadas, considerando suas portas digitais para o controle da velocidade e do acionamento do motor elétrico.

\subsubsection{Dimensionamento do eixo}

Para o dimensionamento do eixo, onde é acoplado a placa com castanha e posteriormente fixado o corpo de prova, considerou-se o esquema simplificado da máquina de fadiga apresentado na Figura 4, onde o ponto " $A$ " representa o início do eixo e seu acoplamento com o motor, os pontos " $\mathrm{B}$ " e " $\mathrm{C}$ " indicam os apoios sobre mancais de rolamento, os pontos “ $\mathrm{D}$ " e " $\mathrm{E}$ " são os pontos de aplicação de carga. 
Figura 4. Modelo simplificado da máquina de fadiga considerando apoios e esforços aplicados ao eixo.

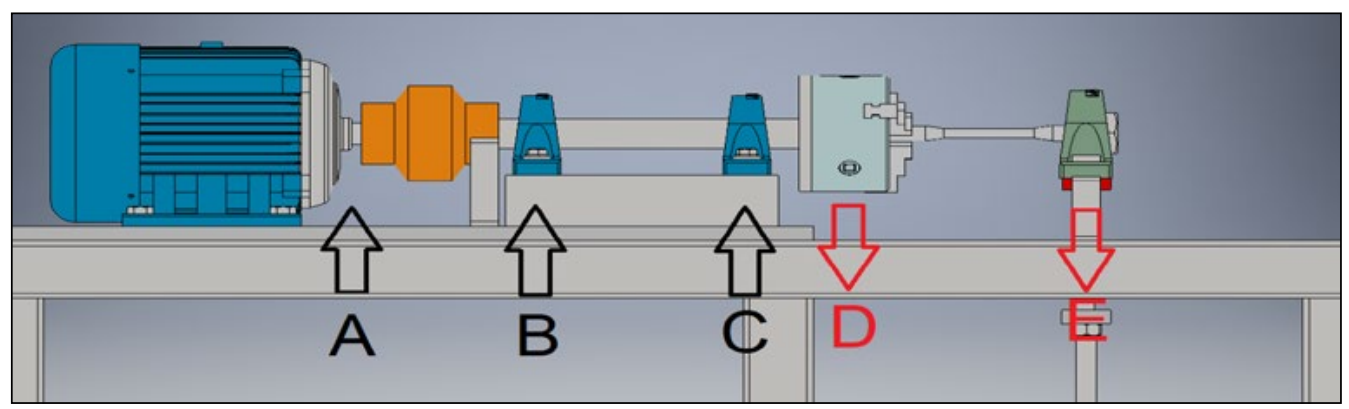

Fonte: Do autor.

O eixo deve suportar as cargas aplicadas em " $\mathrm{D}$ " e " $\mathrm{E}$ ", sendo elas, respectivamente, $123,1 \mathrm{~N} / \mathrm{m}$ (carga gerada pelo conjunto placa de castanha e flange) e $294,3 \mathrm{~N}$ (definida como o limite de carga aplicada ao corpo de prova). Como o eixo deve apresentar um comportamento dúctil e ao mesmo tempo elástico e linear, selecionou-se como material para o eixo o aço SAE 1040 laminado a quente, comprimento de $250 \mathrm{~mm}$ e diâmetro de $25 \mathrm{~mm}$ (essas dimensões levaram em consideração o padrão comercial disponível). Na etapa seguinte, utilizou-se o software Ftool ${ }^{\circledR}$ para obtenção das reações de apoio e dos momentos aplicados ao eixo, como apresentado na Figura 5.

Figura 5. Cargas fornecidas pelo software Ftool: a) forças e reações de apoio; b) momento fletor resultante.

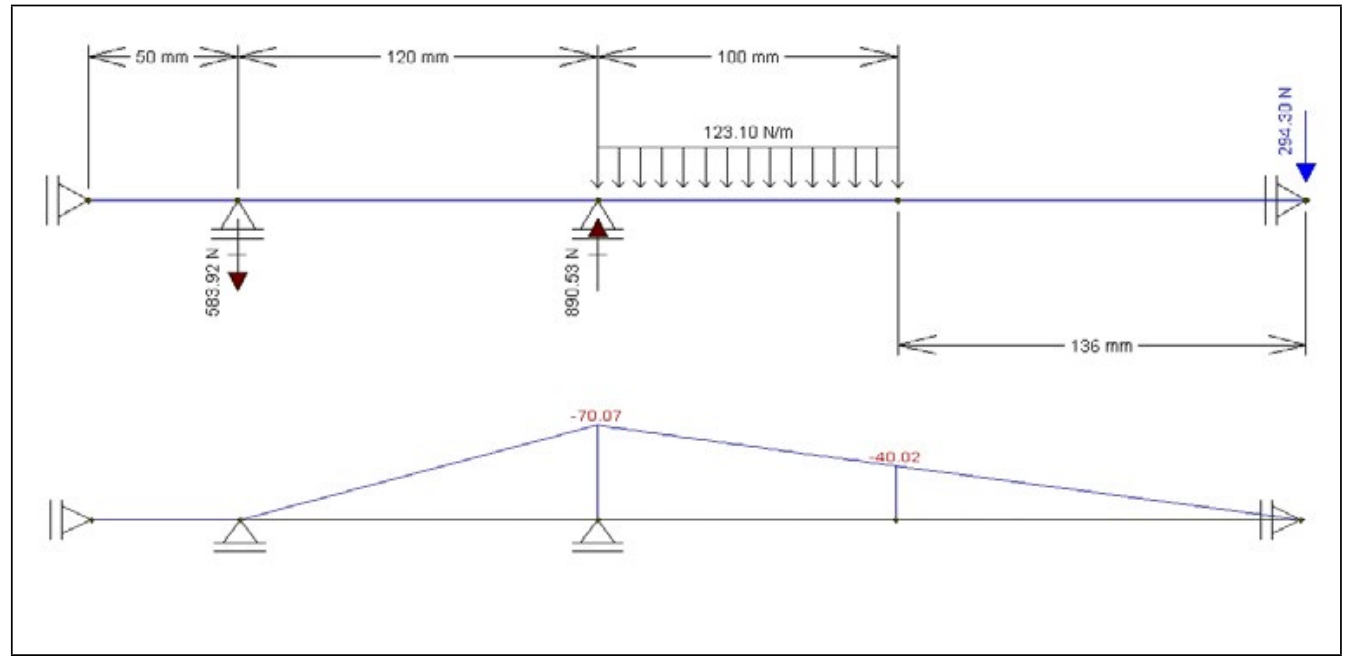

Fonte: Do autor. 
A metodologia de dimensionamento aplicada, bem como valores de constantes para este dimensionamento, foram obtidas de Budynas e Nisbett (2011). Os dados utilizados estão expostos na Tabela 2.

Tabela 2. Constantes referentes ao aço SAE 1040 laminado à quente.

\begin{tabular}{cc}
\hline Descrição & Dados \\
\hline Resistência à tração & $520 \mathrm{MPa}$ \\
Resistência ao escoamento & $290 \mathrm{MPa}$ \\
Fator modificador para acabamento superficial "a" & 57,7 \\
Fator modificador para acabamento superficial " $\mathrm{b}$ ” & 0,718 \\
Fração da resistência à fadiga & 0,89 \\
\hline
\end{tabular}

Fonte: Do autor.

De acordo com Budynas e Nisbett (2011), utilizam-se as seguintes equações para o dimensionamento do eixo:

$$
\begin{gathered}
S e=S u t \cdot 0,5 \cdot k a \cdot k b \\
k_{a}=a \cdot S u t^{b} \\
k_{b}=1,24 \cdot d^{-0,107}
\end{gathered}
$$

Onde: Se é o limite de resistência à fadiga, considerando os fatores modificadores de superfície $k_{a}$ e de tamanho $k_{b}$. Logo, por meio das Equações (1), (2) e (3), tem-se: $S e=148,20 \mathrm{MPa}$. Ainda, de acordo com Budynas e Nisbett (2011), a tensão de flexão é avaliada considerando a Equação (4):

$$
\sigma_{a}=\frac{M \cdot r}{I}
$$

Onde: $\sigma_{a}$ corresponde a tensão completamente reversa; $M$ representa o maior momento fletor experimentado pelo eixo; $r$ corresponde ao raio do eixo e I representa o momento de inércia da seção circular do eixo. $\mathrm{O}$ valor do momento fletor foi obtido na análise do software Ftool, que, através da Figura 5, indica que $M_{\text {máx }}$ é 70,07 N.m, assim $\sigma_{a}$ é 45,68 MPa.

Seguindo, Budynas e Nisbett (2011), o número de ciclos até a falha de um componente é avaliado considerando a Equação (5): 


$$
N=\left\{\sigma a /\left[(f . S u t)^{2} / S e\right\}^{-1 /[(1 / 3) \cdot \log (f . s u t / s e)]}\right.
$$

onde $N$ representa o número de ciclos, em voltas completas.

Os resultados indicam uma vida esperada de $1,26^{\wedge} 10^{9}$ ciclos, o que, segundo Budynas e Nisbett (2011), se caracteriza como vida infinita, uma vez que ao ultrapassar $10^{6}$ ciclos, a relação tensão $\mathrm{x}$ número de ciclos se torna constante. Portanto, o eixo dimensionado é apropriado para realização de ensaios de fadiga sem a ocorrência de eventuais falhas neste componente mecânico, visto que o eixo está dimensionado para realizar 1260 ensaios em sua vida útil.

\subsubsection{Seleção dos mancais}

Para garantir que o sistema de transmissão de rotação permaneça estático axialmente, dois mancais de esferas foram utilizados. Uma vez que cargas estáticas são aplicadas sobre os mancais, através das anilhas e do peso do sistema de transmissão, e estes se encontram em rotação, pode-se considerar que os mancais estarão sujeitos ao desgaste e possivelmente uma falha, por fadiga superficial, após algum tempo. Com base nestes fatores, o projeto destes componentes deve levar em consideração a vida útil que cada mancal terá enquanto estiver sujeito a carregamentos e a máquina estiver em funcionamento.

Para estimar a vida dos mancais de esferas, Norton (2013) sugere uma avaliação na qual avalia a porcentagem de chance de falha do componente, considerando o carregamento estático sobre o mancal que geraria uma vida de um milhão de revoluções, e através deste dado comparativo, o qual é fornecido pelo fabricante, é possível estimar qual será a vida de um mancal de esferas sujeito a um carregamento estático. A Equação (6) é proposta por Norton (2013), para avaliar a vida em fadiga de um mancal.

$$
L_{10}=\left(\frac{C}{P}\right)^{3}
$$

Nesta Equação, $L_{10}$ corresponde a vida em fadiga do mancal expressa em milhões de revoluções considerando uma chance de $10 \%$ de falha; $P$ é a carga constante aplicada; $C$ corresponde a carga dinâmica básica de classificação, ou seja, a carga que corresponde a 1 milhão de ciclos ao mancal. Para a máquina de fadiga foi selecionado um mancal $Y$ com rolamento autocompensador de esferas da marca SKF e modelo YAR 205-100-2F. Este mancal suporta rotações de até $7000 \mathrm{rpm}$. Para o cálculo da vida útil do mancal foi considerado $\mathrm{C}=14$ $\mathrm{kN}$ e $\mathrm{P}=890,53 \mathrm{~N}$; condição que representa o caso extremo de carregamento aplicado sobre o mancal de acordo com a Figura 4. Desta maneira, a vida útil 
estimada para o rolamento, utilizando a Equação (6), é de $\mathrm{L}_{10}=3885,42$ milhões de revoluções. Tendo em vista que a velocidade máxima de rotação do motor é de $1750 \mathrm{rpm}$, a vida estimada para o mancal é de aproximadamente 37004 horas, sendo possível realizar até 3885 ensaios de fadiga com ciclos de vida infinita do corpo de prova.

\subsubsection{Elemento anti vibração e acoplamento elástico}

Um dos fenômenos que influenciam o resultado dos testes de fadiga bem como a integridade mecânica da máquina é a vibração mecânica. Qualquer movimento repetitivo é denominado vibração. De acordo com Rao (2008), "a vibração de um sistema envolve a transferência alternada de sua energia potencial para energia cinética e de energia cinética para energia potencial". Em um sistema amortecido parte dessa energia se dissipa a cada ciclo. Considerando que a máquina projetada contém elementos giratórios e anilhas, responsáveis por fornecer tensões cíclicas ao corpo de provas, esta se torna sujeita a vibrações.

Uma das maneiras mais fáceis e eficazes para o amortecimento de vibrações, de maneira geral, é o emprego de amortecedores de vibração e impacto acoplados à base de máquinas e equipamentos. Estes dispositivos são utilizados com o objetivo de reduzir as vibrações estruturais a níveis muito baixos ou até mesmo nulos. O modelo utilizado neste trabalho, possui corpo de aço com base de borracha e um parafuso para ajuste de altura, tornando-o ideal para o nivelamento da máquina e amortecimento de vibrações decorrente dos ensaios de fadiga.

Ainda, considerando aspectos de dimensionamento da máquina de fadiga, devido a dificuldades de fabricação e montagem, o conjunto motoreixo pode não estar completamente alinhado, estes componentes poderão gerar vibrações consideráveis ao sistema. Para minimizar o problema, foi utilizado um acoplamento elástico de mandíbula. Este dispositivo é composto por duas bases de aço, tendo como função unir o eixo do motor ao eixo principal da máquina, e entre elas, um componente flexível responsável por corrigir pequenos desalinhamentos e amortecer possíveis vibrações. Utilizou-se um acoplamento elástico modelo CM-4, o qual pode ser empregado em eixos de até $35 \mathrm{~mm}$ de diâmetro, suportando um torque máximo de até 98 N.mm e velocidade de até $4200 \mathrm{rpm}$. Considerando que o eixo principal da máquina possui $25 \mathrm{~mm}$ e a velocidade máxima atingida pelo motor elétrico é de 1750 rpm, este modelo se demonstra adequado ao projeto da máquina de fadiga.

A Figura 6 apresenta o amortecedor (marca Vibra Stop modelo Mini) e o acoplamento elástico utilizado na máquina de fadiga. 
Figura 6. Modelo de amortecedor e acoplamento elástico utilizado na máquina de fadiga.

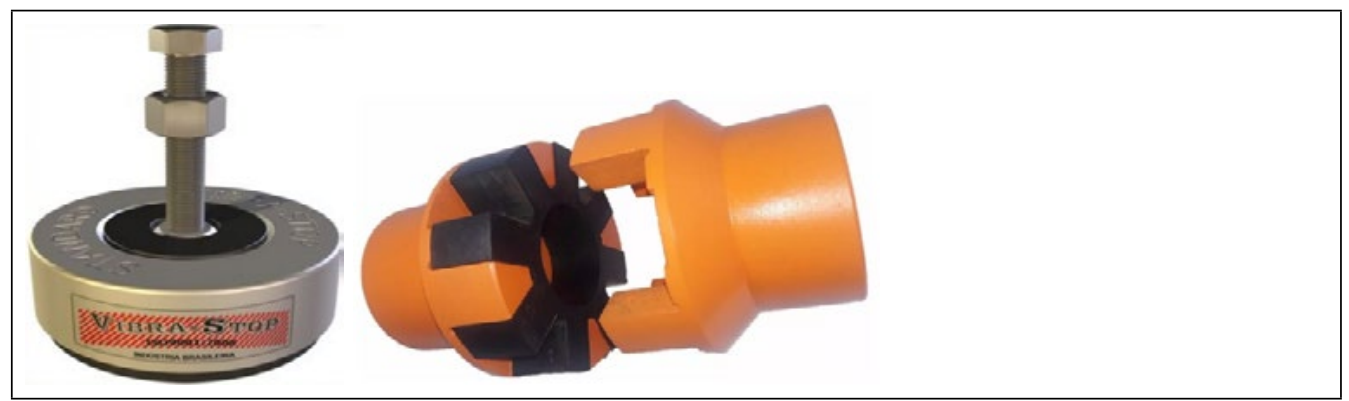

Fonte: Do autor.

\subsubsection{Elementos fixadores do corpo de prova}

Para garantir que o corpo de provas gire em conjunto com o motor e receba a carga radial das anilhas sem afetar sua rotação, elementos fixadores foram empregados na máquina de fadiga. A fixação do corpo de provas ligado ao eixo principal da máquina foi garantida por meio de uma placa com castanhas, a qual permite um bom alinhamento do conjunto e uma fácil remoção do corpo de provas após realização de ensaios experimentais. A fixação do corpo de prova acoplado ao mancal com anilhas, situado no lado em balanço, foi efetuada utilizando uma bucha projetada para ser instalada internamente ao rolamento e presa utilizando um conjunto de rosca e porca. A Figura 7 apresenta o modelo 3D da bucha fabricada para a máquina de fadiga.

Figura 7. Modelo 3D da bucha projetada para a máquina de fadiga.

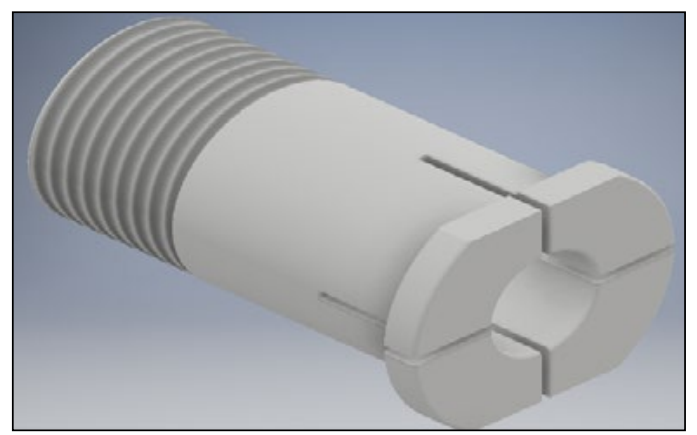

Fonte: Do autor.

O corpo de prova é encaixado no orifício central da bucha, sendo utilizado uma porca rosqueada no lado oposto promovendo o aperto e a 
fixação. Por possuir uma leve inclinação junto aos rasgos, no oposto à rosca, quanto mais a rosca for apertada, mais preso ficará o corpo de prova.

\subsubsection{Instrumentação eletrônica da máquina de fadiga}

Os elementos mecânicos são essenciais para a realização dos ensaios de fadiga, contudo, para que possa ser realizada a contagem do número de ciclos e o controle de acionamento do motor, fez-se necessário a seleção de elementos eletrônicos, conforme apresentado na Figura 8. Para este fim, um sistema eletrônico foi utilizado para contabilizar o número de ciclos suportado pelo corpo de prova até sua ruptura, bem como ligar ou desligar a máquina em casos de emergência ou finalização do ensaio experimental. A eletrônica embarcada no projeto é controlada por uma plataforma Arduino utilizando o dispositivo Arduino Uno R3.

Figura 8. Componentes eletrônicos empregados na instrumentação da máquina.

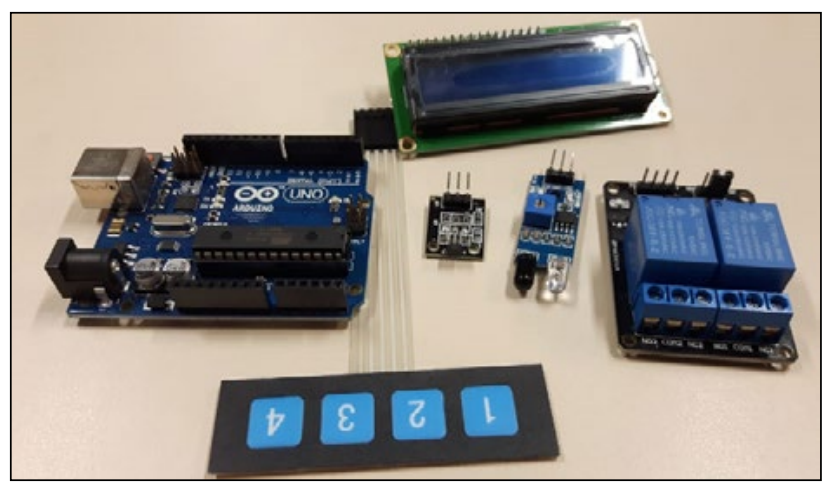

Fonte: Do autor.

Para a contagem do número de ciclos dos ensaios utilizou-se um sensor de Obstáculos Reflexivo Infravermelho. Este sensor envia sinal ao arduino quando algum obstáculo/objeto passa no ângulo de reflexão considerando uma distância ajustada, ou seja, no caso da máquina de fadiga, uma marcação junto ao acoplamento é suficiente para acionar o sensor e contabilizar um ciclo a cada rotação. O número de ciclos contabilizado pelo arduino é demonstrado em tempo real por um Display LCD, onde é possível parar e reiniciar a contagem do número de ciclos, através de um teclado matricial $1 \times 4$.

O controle de desacionamento da máquina é de grande importância para realização dos ensaios e segurança do operador. De acordo com o projeto desenvolvido, a máquina de fadiga em funcionamento deve parar em quatro situações:

1. Desligamento manual através do teclado matricial; 
2. Desligamento manual através de um botão de emergência empregado ao sistema;

3. Desligamento automático após a contagem de 1 milhão de ciclos (considerado vida infinita para a maioria dos aços);

4. Desligamento automático após o rompimento do corpo de provas.

Toda vez que a máquina desacionar, o display irá "congelar" o número de ciclos já contabilizados e o contador irá parar, sendo possível continuar o ensaio posteriormente caso seja necessário. Os controles de desacionamento manual são realizados através do teclado matricial e do botão de emergência. Estes dispositivos são ligados ao arduino, que, quando acionados, envia um sinal a um módulo de relé conectado à entrada digital do inversor de frequência, desligando o motor elétrico. $\mathrm{O}$ desacionamento automático é realizado pelo envio de sinal do arduino para o relé, em primeiro caso, quando o número de ciclos contabilizados for maior que um milhão, e em segundo caso, no rompimento do corpo de prova, o qual é detectado através do uso de um módulo sensor de Efeito Hall e um imã junto ao mancal na extremidade em balanço, que, na ruptura do corpo de prova, perdem contato fazendo o sensor enviar o sinal de desligamento para o Arduino.

\subsection{Análise macroscópica da falha do corpo de prova}

A superfície de fratura do corpo de prova é de grande importância no estudo das falhas causadas pelo fenômeno de fadiga. Portanto, é relevante que a máquina projetada seja capaz de conservar as superfícies de fratura após o ensaio. Fraturas causadas pelo fenômeno de fadiga possuem características peculiares. As marcas de praia indicam o início e o sentido de propagação da trinca, enquanto a zona de fratura rápida demonstra a porção de material resistente até o momento da ruptura final. $\mathrm{O}$ tipo de ensaio e a geometria do corpo de prova são fatores que influenciam nas características da superfície de fratura. A Figura 9 (a) ilustra a superfície de fratura teórica prevista para um carregamento de flexão rotativo, com tensão nominal alta e sem concentrador de tensão, enquanto a Figura 9 (b) demonstra uma visão macroscópica de uma fratura gerada pela máquina de fadiga considerando um corpo de prova. 
Figura 9. a) Ilustração da superfície de fratura prevista pela teoria; b) Fratura do corpo de prova analisado experimentalmente.

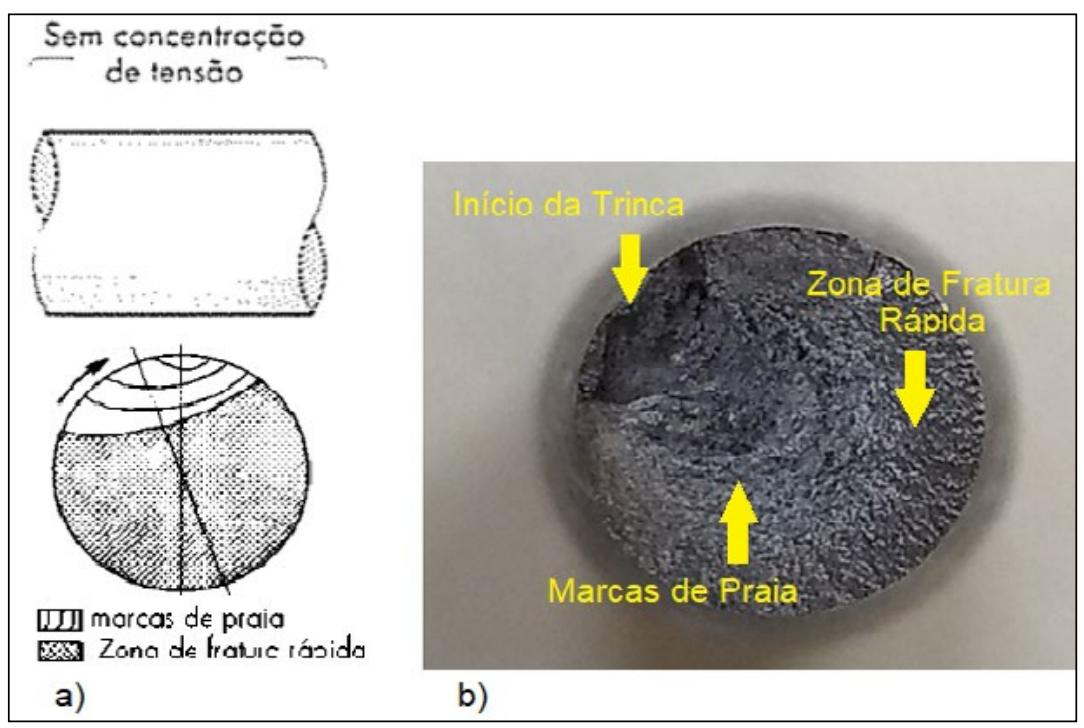

Fonte: a) Adaptado de (BUDYNAS e NISBETT, 2011). b) Do autor.

É possível perceber a semelhança entre o modelo teórico e a superfície do corpo de prova analisado, sendo possível verificar a origem da trinca, as marcas de praia e a zona de fratura rápida. Este comportamento repetiu-se ao longo da realização de mais de 10 testes experimentais realizados.

\subsection{Verificação dos níveis de vibração estrutural da máquina}

Após a construção e instrumentação da máquina, realizaram-se testes para analisar o nível de vibração da máquina em funcionamento. Nesta análise, utilizou-se um acelerômetro MEMS, triaxial, faixa de medição de $\pm 2 \mathrm{~g}$ e sensibilidade de $462 \mathrm{mV} / \mathrm{g}$ além de um sistema de aquisição de dados modelo ADS1800, de 8 canais de medição, taxa de amostragem de $24000 \mathrm{~Hz}$ e 24 bits de resolução. A Figura 10 apresenta os níveis de vibração estrutural da máquina de fadiga em funcionamento. 
Figura 10. Vibração estrutural da máquina de fadiga.

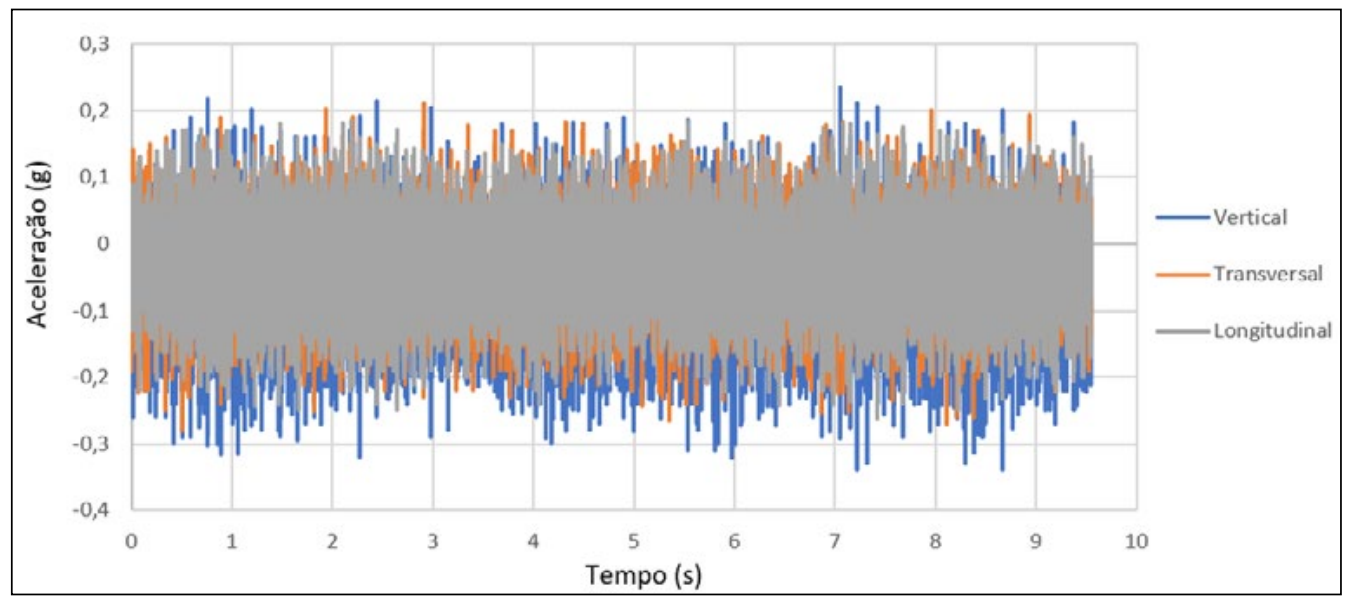

Fonte: do autor.

Durante os ensaios foi utilizada uma taxa de amostragem de $1000 \mathrm{~Hz}$. Ao final das medições foi verificado que os níveis de vibração são ínfimos, ou seja, são níveis muito baixos e não causam alterações nos resultados dos ensaios de fadiga. Comprova-se que a estrutura da máquina é rígida e estável para a realização de testes experimentais.

\subsection{Resultado final da máquina de fadiga}

Após diversas etapas de dimensionamento/seleção de componentes mecânicos e eletrônicos obteve-se a máquina final construída, a qual está apresentada na Figura 11, que está em concordância com o modelo conceitual, demonstrado na Figura 3. 
Figura 11. Máquina de fadiga construída.

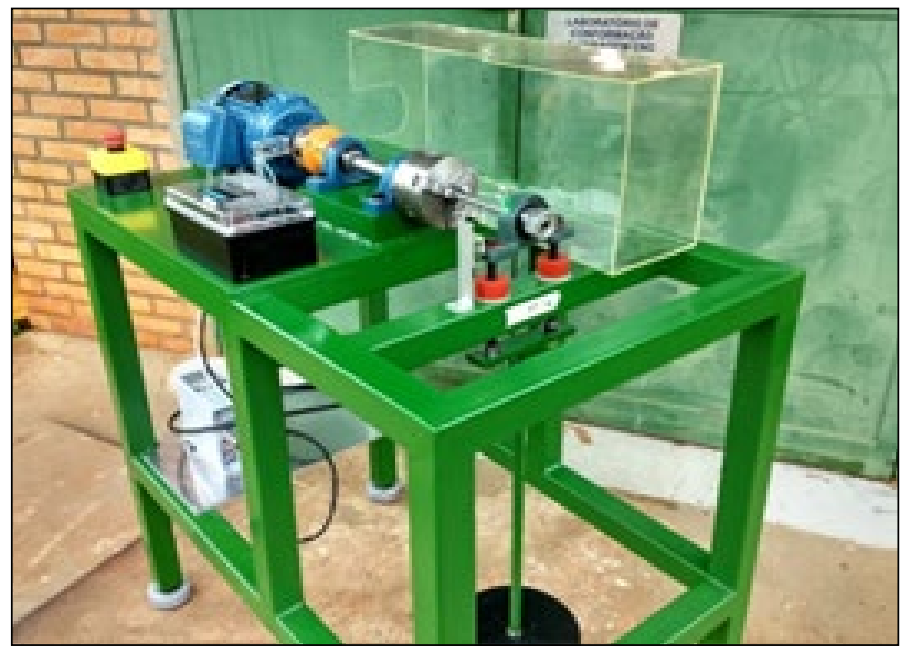

Fonte: do autor.

Alterações mínimas foram realizadas no decorrer da construção da máquina, como a inserção de um suporte para o inversor de frequência, não previsto na concepção inicial do projeto. Na etapa final, realizaram-se ajustes nos elementos anti vibração, visando nivelar a máquina frente ao piso onde a mesma foi instalada.

\section{CONCLUSÃO}

O modelo final da máquina de fadiga foi obtido com êxito, demonstrando-se estável no decorrer dos ensaios mecânicos experimentais. A instrumentação eletrônica, utilizando Arduino UNO, para contagem do número de ciclos até falha de um corpo de prova e controle de acionamento do motor, também apresentou boa exatidão e confiabilidade. No decorrer dos ensaios de validação do equipamento, foram necessários ajustes no elemento transmissor de potência (acoplamento elástico) para garantir o máximo alinhamento e, consequentemente, a diminuição de vibrações mecânicas que poderiam alterar os resultados dos ensaios de fadiga. A análise experimental estrutural utilizando um acelerômetro triaxial, mostra que os níveis de vibração da máquina de fadiga desenvolvida são baixos. O conceito da máquina de fadiga atendeu às condições de solicitações mecânicas, sendo possível realizar ensaios de fadiga com segurança, precisão e confiabilidade. A máquina desenvolvida neste trabalho pode ser usada para fazer diversos testes de materiais, visando caracterizar e utilizar estes materiais no projeto mecânico de diversos componentes. A análise de fadiga em componentes de alta resistência representa um dos testes mais importantes a serem delineados para a avaliação da qualidade do material utilizada no projeto mecânico. 


\section{REFERÊNCIAS}

ABRAHÃO, Rodrigo Rebello Ribeiro et al. FADIGA DE MATERIAIS - UMA REVISÃO BIBLIOGRÁFICA. In: XII SEMINÁRIO DE INICIAÇÃO CIENTÍFICA, 12., 2008, Uberlândia. Anais... . Uberlândia: Ufu, 2008. p. 1 -10.

ALBUQUERQUE, Maria Cléa Soares de. COMPORTAMENTO À FADIGA DE JUNTAS SOLDADAS DE TUBULAÇÕES MARÍTIMAS TRATADAS PELA TÉCNICA TIG DRESSING. 2004. 210 f. Tese (Doutorado) - Curso de Doutorado em Engenharia de Processos, Universidade Federal de Campina Grande, Campina Grande, 2004.

ALVARENGA JÚNIOR, Álvaro; MANSUR, Tanius Rodrigues; PALMA, Ernani Sales. INFLUÊNCIA DA REFRIGERAÇÃO E DA SEQÜÊNCIA DE APLICAÇÃO DE CARGAS EM ENSAIOS DE FADIGA FLEXO-ROTATIVOS NAS PROPRIEDADES MECÂNICAS DO AÇO SAE 8620. In: CONGRESSO NACIONAL DE ENGENHARIA MECÂNICA, 2., 2002, João Pessoa. Procedding. João Pessoa: Conem, 2002. p. 1 - 10.

ANDERSEN, Peter. L. et al. ASM Handbook: Fatigue and Fracture. ASM international. 1997. v. 19.

ANDERSON, Ted L.. Fracture Mechanics. Texas: Crc Press, 2005. 640 p.

ÁVILA, Gabriele Grisolia de.CÁLCULO DE FADIGA DE RISERS RÍGIDOS

ATRAVÉS DA MECÂNICA DA FRATURA. 2005. 237 f. Tese (Doutorado) - Curso de Mestrado em CiÊncias em Engenharia Civil, Universidade Federal do Rio de Janeiro, Rio de Janeiro, 2005.

BRANCO, Carlos A. G. de Mouro; TAVARES, Paulo Manuel Salgado; FERNANDES, Antônio Augusto. Fadiga em Estruturas Soldadas. Lisboa: Fundação Calouse, 1986. 902p.

BUDYNAS, Richard G.; NISBETT, J. Keith. Elementos de máquinas de Shigley: projeto de engenharia mecânica. Tradução de João Batista de Aguiar, José Manoel de Aguiar. 8. ed. rev. Porto Alegre: AMGH, 2011. 1084 p., il. ISBN 9788563308207.

FENG, L.; LIU, X.; XUAN, F. Simulation of Residual Stress in Welded Steam Turbine Rotor and its Effects on Fatigue Life. CHINESE SOCIETY OF ELECTRICAL

ENGINEERING. v. 34, issue 17, p. 2851-2860, june 2012.

MATHEUS, Tibério César Uchôa et al. DISPOSITIVO PARA FLEXÃO ROTATIVA DE FIOS NiTi EM ENSAIO DE FADIGA. Tecnologia em Metalurgia e Materiais, [s.1.], v. 4, n. 4, p.47-52, 2008. Editora Cubo Multimidia. http:/ /dx.doi.org/10.4322/ tmm.00404009.

NORTON, Robert L. Projeto de máquinas: uma abordagem integrada. Tradução de Konstatinos Dimitriou Stavropoulos. 4. ed. Porto Alegre: Bookman, 2013. 1028 p., il., $28,5 \mathrm{~cm}$. ISBN 9788582600221. 
PADILHA, Rodolfo de Queiroz. Influência na vida em fadiga da espessura das camadas de níquel e cromo duro em aço ABNT 4340. 2004. 176 f. Tese (Doutorado) - Curso de Pós Graduação em Engenharia Mecânica, Universidade Estadual Paulista, Guaratinguetá, 2004.

RAO, Singiresu S. Vibrações mecânicas. Tradução de Arlete Simille Marques. 4. ed. São Paulo: Pearson Prentice Hall, 2008. 423 p., il. ISBN 9788576052005.

SOUZA, Sergio A.. Ensaios Mecânicos de Materiais Metálicos. São Paulo: Edgard Blucher, 1982.

TOSO, Marcelo A. et al. Ensaio de fadiga: um comparativo entre dois corpos de provas distintos para aplicação em molas de suspensão automotiva. In: CONGRESSO NACIONAL DE ENGENHARIA MECÂNICA, 9, 2016. Anais... Fortaleza: ABCM, ago. 2016.

WILLMERDING, G.; HACKH, J.; RADOVCIC, Y.. Fatigue Life Design for Wind Turbine Components Using WinLIFE. In: NAFEMS WORLD CONGRESS, 1., 2011, Boston. Anais... . Boston: -, 2011. p. 1 - 16.

XIANG, Hui Yu et al. Fatigue Analysis of the Rotor Shaft on a High Speed Traction Motor. Advanced Materials Research, [s.1.], v. 482-484, p.722-725, fev. 2012. Trans Tech Publications. http:/ / dx.doi.org/10.4028/www.scientific.net/amr.482-484.722. 